\title{
Warfarin Resistance: A Case Report
}

\author{
(1) Uğur Gönlügür ${ }^{1}$, (1) Tanseli Gönlügür ${ }^{2}$, (1) Öztürk Özdemir ${ }^{3}$, (1) Fatma Sılan ${ }^{3}$ \\ 1Department of Chest Diseases, Çanakkale Onsekiz Mart University Faculty of Medicine, Çanakkale, Turkey \\ ${ }^{2}$ Clinic of Chest Diseases, Çanakkale City Hospital, Çanakkale, Turkey \\ ${ }^{3}$ Department of Medical Genetics, Çanakkale Onsekiz Mart University Faculty of Medicine, Çanakkale, Turkey
}

\begin{abstract}
Warfarin is the most widely prescribed anticoagulant in the world. Patients who need more than 15 mg per day should be considered warfarin-resistant. Nearly 30 genes have been reported in association with warfarin pharmacogenetics but genetic polymorphisms in the genes encoding CYP2C9 and VKORC1 have been shown to act as the most important determinants of drug dosage requirements. The major enzyme responsible for the metabolism of S-warfarin, the more potent of warfarin's two stereoisomers, is CYP2C9. Warfarin inhibits vitamin K epoxide reductase (VKOR). A 30-year-old woman was referred to our clinic for pulmonary embolism. She was treated with low molecular weight heparin. The warfarin dose was titrated up to $15 \mathrm{mg}$ daily but after one week, the INR (international normalized ratio) was still subtherapeutic level at 1.8. In this paper, we discuss underlying genetic polymorphisms about warfarin resistance.
\end{abstract}

Keywords: Warfarin, vitamin K epoxide reductases, VKORC1

\section{Introduction}

An outbreak was observed cattle in the Northern USA and Canada in the 1920s. The disease was characterised by fatal bleeding, either spontaneously or from minor injuries. Nearly 20 years later, Karl Link discovered that the anticoagulant in sweet clover was 3,3'-methylenebis (4-hydroxy coumarin). Further work by Link led in 1948 to the synthesis of warfarin. The name warfarin is derived from the sponsor (Wisconsin Alumni Research Foundation) and -arin from coumarin (1).

The glutamate residues in some coagulation factors (II, VII, $\mathrm{IX}, \mathrm{X})$ are carboxylated in presence of $\mathrm{O}_{2}, \mathrm{CO}_{2}$, and the enzyme carboxylase, to form $\gamma$ - carboxyglutamate (Gla) residues. Vitamin $\mathrm{K}$ is essential for this post translational modification in the liver. In this process, vitamin $\mathrm{K}$ hydroquinone converted to vitamin $\mathrm{K}$ epoxide. Then, vitamin K epoxide reductase (VKOR) turned its epoxide to vitamin $\mathrm{K}$ again. Warfarin exerts its anticoagulant effect by inhibiting (2) the protein vitamin $\mathrm{K}$ epoxide reductase complex, subunit 1 (VKORC1).
The frequency of referral of patients with warfarin related complications to the emergency unit increases (3). The patients with warfarin resistance can present atypical chest pain due to pulmonary emboli $(4,5)$. Intracardiac thrombi can develop during warfarin therapy in such cases (6). Warfarin resistance defined as warfarin requirements greater than $15 \mathrm{mg}$ per day to maintain the international normalised ratio (INR) in the target therapeutic range (7). We present a patient with warfarin resistance who had related mutations.

\section{Case Report}

A 30-year-old woman was admitted to the outpatient clinic of chest department of the city hospital for chest pain. Her medical history was unremarkable. Chest computed tomography (CT)angiogram was consistent with pulmonary embolism. The patient's initial treatment was low-molecular-weight heparin. A loading dose of warfarin $5 \mathrm{mg}$ daily was started at the second day of admission. The warfarin dose was titrated up to $15 \mathrm{mg}$ daily for one week, the INR was still subtherapeutic at 1.8. She did not 
report any dietary changes or other drug intake. We performed genetical analyses to explain warfarin resistance. Warfarin therapy was stopped and low-molecular-weight heparin was started again.

Real time technique was used in the genotype analysis of target genes in current proband patient. Total genomic DNA was extracted from peripheral blood sample from patient with spin column extraction technique (Roche). SERPINC1 gene was sequenced with Genetic analyser (ABI Prism 3130, Germany) and target thrombophila genes of factor V Leiden, factor II, MTHFR C677T and A1298G, PAl1, exon 7 of CYP2C9*2*3 (rs1057910) and promoter region of VKORC1 (rs9923231) were amplified by using real-time PCR technique (LightCycler 2.0, Roche). Case was intermediate metabolising profile for the CYP2C9 gene (CYP2C9*1/*2), Both SNPs (C677T and A1298C) were also in heterozygous mutated profile for target MTHFR gene. Heterozygous point mutation was detected in VKORC1 -1639>A allele in the current proband case with warfarin resistance. The rest of genes that analysed (factor V Ledien, factor II, PAI-1 and SERPINC1) were in normal structure.

\section{Discussion}

It has been shown that methylenetetrahydrofolate reductase C677T and A1298C, plasminogen activator inhibitor-1(PAI-1) $4 \mathrm{G} / 5 \mathrm{G}$ mutations were associated with an increased risk of deep venous thrombosis (8). We did not find any other predisposing factors related to pulmonary embolism in our case.

Combining age and body surface area together with genetic polymorphisms in CYP2C9 and VKORC1 accounted for $55 \%$ of the variance in dosage requirements (1). The daily warfarin doses of patients with the $C Y P 2 C C^{*} 1 / * 2$ were not significantly different from those of patients with the wild-type $\left(\mathrm{CYP} 2 \mathrm{C} 9^{*} 1 /{ }^{*} 1\right)$ mutation in Turkish population (9). Consequently, we suggested that CYP2C9*1/*2 mutation found in our patient did not contribute to warfarin resistance.

In Turkish patients, VKORC1-1639 G>A polymorphism found approximately $15 \%$ of the inter-individual variability in the warfarin dose requirement as the largest contribution (9). Mean dose was reported as $5 \mathrm{mg}$ in wild-type GG mutation but 3.5 $\mathrm{mg}$ in the heterozygous (AG) group. Because our patient had heterozygous mutation, we cannot explain warfarin resistance via this mechanism. In Turkey, it has been shown that GG mutation had a higher dosage requirement for warfarin compared with the other genotypes (10). On the other hand, in Chinese population, warfarin maintenance doses in $A G+G G$ carriers were higher than those in AA carriers (11).
D'Andrea et al. (12) reported that the mean dose of warfarin was higher $(6.2 \mathrm{mg})$ among Caucasian patients with the VKORC1 $1173 C \mathrm{C}$ genotype than those of patients carrying the CT (4.8 mg) or the TT genotype $(3.5 \mathrm{mg})$. In Chinese patients, warfarin dose was apparently higher in patients with CT genotype $(3.8 \mathrm{mg})$ as compared with patients with TT genotype (3.1 mg). There is no study about VKORC1 1173 genotyping in Turkish patients. Turkish society is composed of people of many different ethnic backgrounds such as Turkish, Asian, and Caucasian.

The in vitro analysis revealed that only six mutations of the VKORC1 (A26P, A41S, V54L, H68Y, I123N and Y139H) have been found to be associated with warfarin resistance among more than 26 missense mutations (2). Our study has limitation because of the absence of investigations for constitutional mutations of VKORC1. We could perform only VKORC1 promoter G-1639A and first intron C1173T polymorphisms genotyping in our patient.

\section{Conclusion}

In conclusions, warfarin resistance in the present case was still unknown. We continued low-molecular-weight heparin in our patient. Ethnic difference is important because of other genes and other rare polymorphisms affect warfarine metabolism. In addition to CYP2C9 and VKORC1, polymorphisms in other genes that may help determine the dose of warfarin should be investigated.

\section{Ethics}

Informed Consent: It was taken.

Peer-review: Externally peer-reviewed.

\section{Authorship Contributions}

Surgical and Medical Practices: U.G., T.G., Concept: U.G., T.G., Design: U.G., T.G., F.S., Ö.Ö., Data Collection or Processing: U.G., T.G., Analysis or Interpretation: U.G., T.G., Literature Search: U.G., T.G., Writing: U.G., T.G., F.S., Ö.Ö.

Conflict of Interest: No conflict of interest was declared by the authors.

Financial Disclosure: The authors declared that this study received no financial support.

\section{References}

1. Pirmohamed M. Warfarin: almost 60 years old and still causing problems. $\mathrm{Br}$ J Clin Pharmacol. 2006;62:509-11.

2. Hodroge A, Matagrin B, Moreau C, Fourel I, Hammed A, Benoit E, et al. VKORC1 mutations detected in patients resistant to vitamin $\mathrm{K}$ antagonists are not all associated with a resistant VKOR activity. J Thromb Haemost. 2012;10:2535-43

3. Altunbaș G, Ercan S, Davutoğlu V, Al B. Overview of warfarin treatment and answers to questions. The Journal of Academic Emergency Medicine. 2013;12:38-42 
4. Sabol BJ, Basa RR, Wilkins CE. Malabsorption-associated warfarin resistance. Am J Health Syst Pharm. 2009;66:1548-53.

5. Sattar A, Willman JE, Kolluri R. Possible warfarin resistance due to interaction with ascorbic acid: case report and literature review. Am J Health Syst Pharm. 2013;70:782-6.

6. Pescetelli I, Genovesi E, Renda G, Di Renzo E, De Caterina R. Intracardiac thrombi during warfarin anticoagulation - A case report and a brief literature review. Cor et Vasa 2017;59:e277-81.

7. Osinbowale 0, Al Malki M, Schade A, Bartholomew JR. An algorithm for managing warfarin resistance. Cleve Clin J Med. 2009;76:724-30.

8. Hosseini S, Kalantar E, Hosseini MS, Tabibian S, Shamsizadeh M, Dorgalaleh A. Genetic risk factors in patients with deep venous thrombosis, a retrospective case control study on Iranian population. Thromb J. 2015;13:35.
9. Yildirim E, Erol K, Birdane A. Warfarin dose requirement in Turkish patients: the influences of patient characteristics and polymorphisms in CYP2C9, VKORC1 and factor VII. Hippokratia. 2014;18:319-27.

10. Yardım O, Emektar E, Çevik Y, Çorbacıoğlu ȘK, Karabulut AE. Evaluation of the VKORC1 and CYP2C9 gene polymorphisms and their effects on the emergency complications in the patients using warfarin. Eurasian J Emerg Med. 2017; 16:65-9.

11. Yan X, Yang F, Zhou H, Zhang H, Liu J, Ma K, et al. Effects of VKORC1 genetic polymorphisms on warfarin maintenance dose requirement in a Chinese Han population. Med Sci Monit. 2015;21:3577-84.

12. D'Andrea G, D'Ambrosio RL, Di Perna P, Chetta M, Santacroce R, Brancaccio $\mathrm{V}$, et al. A polymorphism in the VKORC1 gene is associated with an interindividual variability in the dose-anticoagulant effect of warfarin. Blood. 2005;105:645-64. 